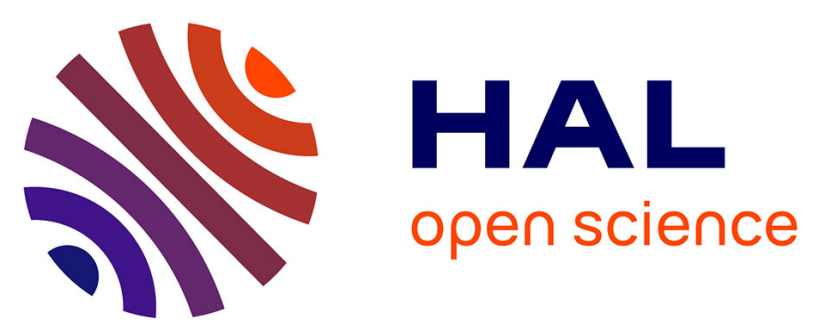

\title{
A LOWER INITIAL ABUNDANCE OF SHORT-LIVED 41 Ca IN THE EARLY SOLAR SYSTEM AND ITS IMPLICATIONS FOR SOLAR SYSTEM FORMATION
}

Ming-Chang Liu, Marc Chaussidon, Gopalan Srinivasan, Kevin Mckeegan

\section{To cite this version:}

Ming-Chang Liu, Marc Chaussidon, Gopalan Srinivasan, Kevin Mckeegan. A LOWER INITIAL ABUNDANCE OF SHORT-LIVED 41 Ca IN THE EARLY SOLAR SYSTEM AND ITS IMPLICATIONS FOR SOLAR SYSTEM FORMATION. The Astrophysical Journal, 2012, 761 (2), 10.1088/0004-637x/761/2/137 . insu-01878078

\section{HAL Id: insu-01878078 https://hal-insu.archives-ouvertes.fr/insu-01878078}

Submitted on 20 Sep 2018

HAL is a multi-disciplinary open access archive for the deposit and dissemination of scientific research documents, whether they are published or not. The documents may come from teaching and research institutions in France or abroad, or from public or private research centers.
L'archive ouverte pluridisciplinaire HAL, est destinée au dépôt et à la diffusion de documents scientifiques de niveau recherche, publiés ou non, émanant des établissements d'enseignement et de recherche français ou étrangers, des laboratoires publics ou privés. 


\title{
A LOWER INITIAL ABUNDANCE OF SHORT-LIVED ${ }^{41}$ Ca IN THE EARLY SOLAR SYSTEM AND ITS IMPLICATIONS FOR SOLAR SYSTEM FORMATION
}

\author{
Ming-Chang Liu $^{1}$, Marc Chaussidon ${ }^{2}$, Gopalan Srinivasan ${ }^{3}$, and Kevin D. McKeEgan ${ }^{4}$ \\ ${ }^{1}$ Institute of Astronomy and Astrophysics, Academia Sinica, Taipei, Taiwan; mcliu@ asiaa.sinica.edu.tw \\ ${ }^{2}$ Centre de Recherches Pétrographiques et Géochimiques, CNRS, Nancy, France \\ ${ }^{3}$ Center for Earth Science, Indian Institute of Science, Bangalore, India \\ ${ }^{4}$ Department of Earth and Space Sciences, UCLA, Los Angeles, CA, USA \\ Received 2012 September 13; accepted 2012 November 1; published 2012 December 4
}

\begin{abstract}
The short-lived radionuclide ${ }^{41} \mathrm{Ca}$ plays an important role in constraining the immediate astrophysical environment and the formation timescale of the nascent solar system due to its extremely short half-life (0.1 Myr). Nearly 20 years ago, the initial ratio of ${ }^{41} \mathrm{Ca} /{ }^{40} \mathrm{Ca}$ in the solar system was determined to be $(1.41 \pm 0.14) \times 10^{-8}$, primarily based on two Ca-Al-rich Inclusions (CAIs) from the CV chondrite Efremovka. With an advanced analytical technique for isotopic measurements, we reanalyzed the potassium isotopic compositions of the two Efremovka CAIs and inferred the initial ratios of ${ }^{41} \mathrm{Ca} /{ }^{40} \mathrm{Ca}$ to be $(2.6 \pm 0.9) \times 10^{-9}$ and $(1.4 \pm 0.6) \times 10^{-9}(2 \sigma)$, a factor of $7-10$ lower than the previously inferred value. Considering possible thermal processing that led to lower ${ }^{26} \mathrm{Al} /{ }^{27} \mathrm{Al}$ ratios in the two CAIs, we propose that the true solar system initial value of ${ }^{41} \mathrm{Ca} /{ }^{40} \mathrm{Ca}$ should have been $\sim 4.2 \times 10^{-9}$. Synchronicity could have existed between ${ }^{26} \mathrm{Al}$ and ${ }^{41} \mathrm{Ca}$, indicating a uniform distribution of the two radionuclides at the time of CAI formation. The new initial ${ }^{41} \mathrm{Ca}$ abundance is $4-16$ times lower than the calculated value for steady-state galactic nucleosynthesis. Therefore, ${ }^{41} \mathrm{Ca}$ could have originated as part of molecular cloud materials with a free decay time of 0.2-0.4 Myr. Alternative possibilities, such as a last-minute input from a stellar source and early solar system irradiation, could not be definitively ruled out. This underscores the need for more data from diverse CAIs to determine the true astrophysical origin of ${ }^{41} \mathrm{Ca}$.
\end{abstract}

Key words: meteorites, meteors, meteoroids - nuclear reactions, nucleosynthesis, abundances - protoplanetary disks

\section{INTRODUCTION}

Studies of the initial abundance and distribution of the shortlived radionuclide ${ }^{41} \mathrm{Ca}$ (decays to ${ }^{41} \mathrm{~K}$ with a $t_{1 / 2}=0.1 \mathrm{Myr}$; Jörg et al. 2012) in the early solar system provide important constraints on the origin of this radioactivity, which is crucial for understanding the astrophysical environment in which the Sun was born. The origin of ${ }^{41} \mathrm{Ca}$ (and some other radioactivities with half-lives around a few Myr present in the early solar system) still remains a matter of debate. From theoretical viewpoints, ${ }^{41} \mathrm{Ca}$ can be delivered into the solar nebula as a nucleosynthetic product of different stars (supernova (SN), asymptotic giant branch (AGB) stars, or Wolf-Rayet (WR) stars) and/or is produced by nuclear reactions induced by energetic charged particles bombarding ambient gas or dust near the proto-Sun (e.g., Meyer 2005; Lee et al. 1998; Gounelle et al. 2001, 2006; Arnould et al. 2006; Wasserburg et al. 2006). These contrasting origins would then have different implications for the processes and timescales of solar system formation (Dauphas \& Chaussidon 2011). In a stellar origin hypothesis, the expected uniformity of ${ }^{41} \mathrm{Ca}$ abundance in the solar nebula (as a result of hydrodynamic mixing, e.g., Boss 2007, 2011) would not only make it potentially useful for chronology, but also provides a stringent constraint on the time span between its nucleosynthesis and incorporation into the early solar system material. In contrast, in situ irradiation production could have resulted in variable ${ }^{41} \mathrm{Ca}$ abundances throughout the nebula, rendering chronological applications invalid. It is however not possible to favor one source over the other unless a comprehensive understanding of the abundances of ${ }^{41} \mathrm{Ca}$ and its relationship with other short-lived radioisotopes in the oldest solar system materials, namely $\mathrm{Ca}-\mathrm{Al}$-rich Inclusions (CAIs), is constructed.
In the past 20 years, there have only been limited data reported for ${ }^{41} \mathrm{Ca}$ primarily due to analytically challenging mass spectrometry (see below). Earlier studies carried out on smallgeometry Secondary Ion Mass Spectrometers (SIMS) have revealed large excesses of radiogenic ${ }^{41} \mathrm{~K}\left(\equiv{ }^{41} \mathrm{~K}^{*}\right)$ in correlation with the ${ }^{40} \mathrm{Ca} /{ }^{39} \mathrm{~K}$ ratios of the phases (primarily fassaite, a Ti-rich pyroxene) measured in CAIs from the CV3 chondrites Allende and Efremovka and a CM2 chondrite Murchison, indicating the existence of ${ }^{41} \mathrm{Ca}$ in the early solar system at the level of ${ }^{41} \mathrm{Ca} /{ }^{40} \mathrm{Ca} \sim 1.4 \times 10^{-8}$, albeit with large analytical uncertainties (Srinivasan et al. 1996; Sahijpal et al. 2000). Such a discovery implies, if ${ }^{41} \mathrm{Ca}$ was injected into the solar nebula from a dying star, a short timescale ( $<1 \mathrm{Myr})$ for its nucleosynthetic production, transit, and incorporation into CAIs (Srinivasan et al. 1996). This interpretation was strengthened by the later discovery of the correlated presence or absence between ${ }^{26} \mathrm{Al}$ $\left(t_{1 / 2}=0.7 \mathrm{Myr}\right)$ and ${ }^{41} \mathrm{Ca}$ in both CV CAIs and CM hibonite $\left(\mathrm{CaAl}_{12} \mathrm{O}_{19}\right)$ grains: samples characterized by the "canonical" ${ }^{26} \mathrm{Al} /{ }^{27} \mathrm{Al} \sim 5 \times 10^{-5}$ contained ${ }^{41} \mathrm{Ca} /{ }^{40} \mathrm{Ca} \sim 1.4 \times 10^{-8}$; in contrast, the ${ }^{26} \mathrm{Al}$-free inclusions were devoid of ${ }^{41} \mathrm{Ca}$ (Sahilpal et al. 1998). Given that widespread ${ }^{26} \mathrm{Al} /{ }^{27} \mathrm{Al}=5.2 \times 10^{-5}$ in the early solar system during CAI formation is believed to have resulted from an injection of ${ }^{26} \mathrm{Al}$ from a stellar source followed by hydrodynamic mixing in the nebula (e.g., Boss 2007, 2011), this correlation could then be understood as a consequence of co-injection and co-homogenization in the solar nebula after some CAIs have formed (Sahijpal \& Goswami 1998).

It should, however, be noted that the assessment of true ${ }^{41} \mathrm{~K}^{*}$ level in a mineral relies significantly on the accuracy of estimates and correction for all interferences at mass/charge $(\mathrm{m} / \mathrm{e}) 41$. For example, three different initial ${ }^{41} \mathrm{Ca} /{ }^{40} \mathrm{Ca}$ ratios, $(8 \pm 3) \times$ $10^{-9},(1.2 \pm 0.2) \times 10^{-8}$, and $(4.1 \pm 2.0) \times 10^{-9}$, inferred from the isotope analyses performed on small-geometry SIMS 


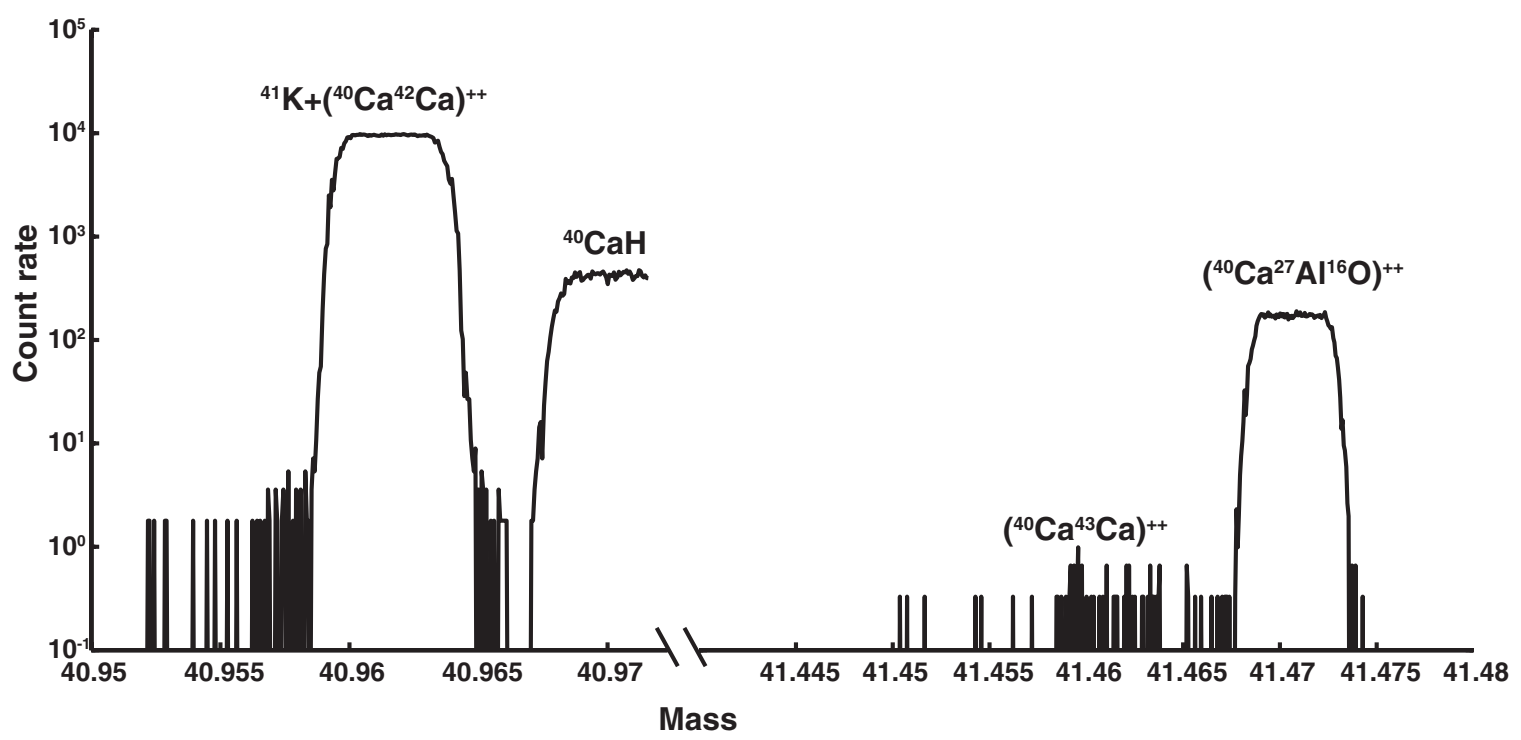

Figure 1. Mass spectrum obtained on a hibonite standard at $m / e=41$ and 41.5 on the CAMECA $1280 \mathrm{HR} 2$ ion microprobe at CRPG, Nancy, at a mass resolution $=$ 8000. Extra counts on the low-mass side of $\left({ }^{40} \mathrm{Ca}^{43} \mathrm{Ca}\right)^{++}$are derived from the dynamic background.

(the first two; see Hutcheon et al. 1984 and Sahijpal et al. 2000) and large-geometry SIMS (the last one; Ito et al. 2006), have been reported for the CAI EGG3. Although these controversial results have been attributed to isotope disturbances of potassium in that CAI by Sahijpal et al. (2000) and Ito et al. (2006), the robustness of corrections for all the peaks interfering with ${ }^{41} \mathrm{~K}$ could have also been a cause. The large systematic uncertainties derived from deconvolving the interferences from real ${ }^{41} \mathrm{~K}^{*}$ and the limited amount of data available so far have not allowed for a quantitative evaluation of the level of ${ }^{41} \mathrm{Ca} /{ }^{40} \mathrm{Ca}$ in the solar nebula. To better quantify the true initial ${ }^{41} \mathrm{Ca}$ abundance, the first step is to reexamine the potassium isotopic compositions with a new high mass-resolution, high transmission ion microprobe (SIMS) in the CAIs where fossil records of ${ }^{41} \mathrm{Ca}$ have been previously demonstrated. Here we report the new isotopic results of the ${ }^{41} \mathrm{Ca}-{ }^{41} \mathrm{~K}$ system in two CAIs from Efremovka, where evidence of in situ decay of ${ }^{41} \mathrm{Ca}$ was revealed (Srinivasan et al. 1996), and discuss the implications for the origins of short-lived ${ }^{41} \mathrm{Ca}$ and solar system formation.

\section{EXPERIMENTAL}

\subsection{Samples}

The samples studied here are the E44 and E65 CAIs from the $\mathrm{CV}$ chondrite Efremovka. They are of particular importance in potassium isotopic analyses because the prior existence of ${ }^{41} \mathrm{Ca} /{ }^{40} \mathrm{Ca}=1.4 \times 10^{-8}$ in the solar system was primarily inferred in them (Srinivasan et al. 1996). Other earlier studies on their petrology, mineral chemistry, and magnesium and boron isotopic compositions can be found in Goswami et al. (1994), Young et al. (2005), McKeegan et al. (2001), and Srinivasan \& Chaussidon (2012). Recent high precision analyses of $\mathrm{Mg}$ isotopes revealed that E44 and E65 are characterized by ${ }^{26} \mathrm{Al} /{ }^{27} \mathrm{Al}$ ratios of $(4.8 \pm 0.3) \times 10^{-5}$ and $(4.46 \pm 0.25) \times$ $10^{-5}$ (Young et al. 2005; Srinivasan \& Chaussidon 2012), respectively. The two inclusions have also been shown to preserve fossil records of ${ }^{10} \mathrm{Be}\left(t_{1 / 2}=1.3 \mathrm{Myr}\right.$; Korschinek et al. $2010)$, with ${ }^{10} \mathrm{Be} /{ }^{9} \mathrm{Be}=(8.4 \pm 1.9) \times 10^{-4}$ and $(7.0 \pm$ 1.7) $\times 10^{-4}$ consistent with one another within analytical uncertainties (McKeegan et al. 2001; Srinivasan \& Chaussidon 2012).

\subsection{Mass Spectrometry}

Measurements of potassium isotopes were made on the CAMECA 1280 HR2 ion microprobe at CRPG, Nancy. The major challenge in obtaining the true radiogenic component of ${ }^{41} \mathrm{~K}$ is to accurately quantify the magnitudes of all interferences at $m / e=41$, including $\left({ }^{40} \mathrm{Ca}^{42} \mathrm{Ca}\right)^{++}$and scattered ions from ${ }^{40} \mathrm{Ca}^{+}$and ${ }^{40} \mathrm{CaH}^{+}$tails, and correct for them. Given that the initial ${ }^{41} \mathrm{Ca} /{ }^{40} \mathrm{Ca}$ ratio in the early solar system appears to be $\approx 10^{-8}$, only phases with ${ }^{40} \mathrm{Ca} /{ }^{39} \mathrm{~K}$ exceeding $5 \times 10^{5}$ (K concentrations $<200 \mathrm{ng} \mathrm{g}^{-1}$ ) could potentially provide large enough ${ }^{41} \mathrm{~K}$ excesses compared to the analytical errors. However, two problems come with such high ${ }^{40} \mathrm{Ca} /{ }^{39} \mathrm{~K}$ ratios. First, low $\mathrm{K}$ count rates, especially at mass 41 , limit the analytical precision. Second, intensities of Ca-related interferences at $m / e=41$ become significant relative to that of ${ }^{41} \mathrm{~K}^{+}$, making accurate determinations of ${ }^{41} \mathrm{~K} /{ }^{39} \mathrm{~K}$ ratios very difficult. These challenges, in theory, could be eased by using a large-geometry SIMS, whose high throughput and high mass resolution (compared to those of smaller ones, e.g., CAMECA 3-7f) help improve analytical precision as well as separation between interferences and the peaks of interest.

The $1280 \mathrm{HR} 2$ was operated with a mass resolution $(M / \Delta M)$ of 8000 , sufficient to separate ${ }^{40} \mathrm{CaH}^{+}$from ${ }^{41} \mathrm{~K}^{+}$, and other minor interferences from the peaks of interests (Figure 1). Since the major interference at mass $41,\left({ }^{40} \mathrm{Ca}^{42} \mathrm{Ca}\right)^{++}$, was not resolvable under any available mass resolution $(M / \Delta M=$ 34,000 is needed), we estimated its contribution indirectly by assuming that the following equality holds (see Hutcheon et al. 1984; Srinivasan et al. 1996):

$$
\frac{\left({ }^{40} \mathrm{Ca}^{42} \mathrm{Ca}\right)^{++}}{{ }^{42} \mathrm{Ca}^{+}}=\frac{\left({ }^{40} \mathrm{Ca}^{43} \mathrm{Ca}\right)^{++}}{{ }^{43} \mathrm{Ca}^{+}},
$$

$\left({ }^{40} \mathrm{Ca}^{43} \mathrm{Ca}\right)^{++}$can be found at $m / e=41.5$. Due to its extremely low intensity $\left(<1\right.$ counts $\left.\mathrm{s}^{-1}\right)$, the location of $\left({ }^{40} \mathrm{Ca}^{43} \mathrm{Ca}\right)^{++}$ (41.4607 amu) was set by anchoring the magnetic field to the reference peak $\left({ }^{40} \mathrm{Ca}^{27} \mathrm{Al}^{16} \mathrm{O}\right){ }^{++}(41.4695 \mathrm{amu})$. The high transmission of the instrument enabled the measurement of $\left({ }^{40} \mathrm{Ca}^{43} \mathrm{Ca}\right)^{++}$to determine $\left({ }^{40} \mathrm{Ca}^{43} \mathrm{Ca}\right){ }^{++} /{ }^{43} \mathrm{Ca}^{+}$for every spot analysis, as opposed to stand-alone characterizations of this ratio 


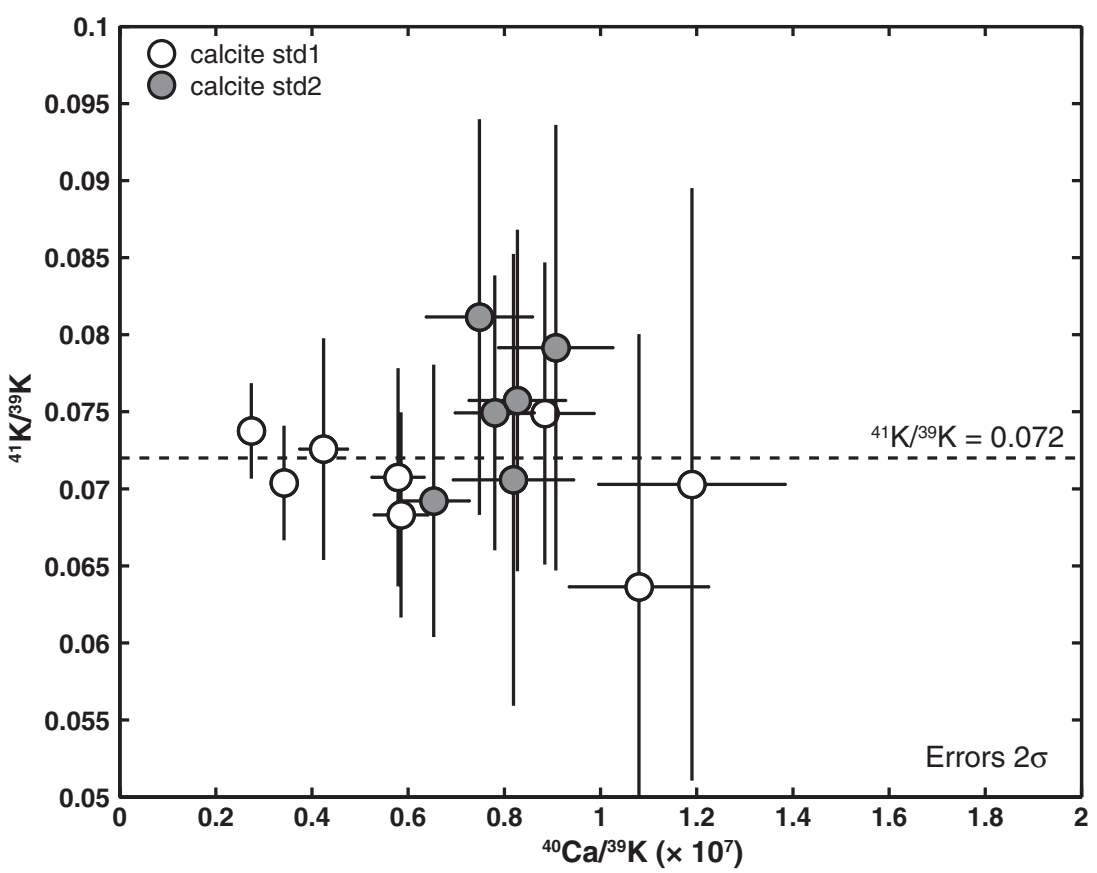

Figure 2. Potassium isotopic compositions of the two terrestrial calcite standards. The ${ }^{41} \mathrm{~K} /{ }^{39} \mathrm{~K}$ ratios obtained are consistent with the terrestrial ratio (dashed line). Errors are $2 \sigma$.

independent of $\mathrm{K}$ isotope analyses (see Srinivasan et al. 1996). We confirmed that $\left({ }^{40} \mathrm{Ca}^{43} \mathrm{Ca}\right)^{++} /{ }^{43} \mathrm{Ca}^{+}$is matrix dependent (Hutcheon et al. 1984; Srinivasan et al. 1996), and the values obtained here are identical within errors to those in Srinivasan et al. (1996). We used the measured $\left({ }^{40} \mathrm{Ca}^{43} \mathrm{Ca}\right)^{++} /{ }^{43} \mathrm{Ca}^{+}$ratio in each run to estimate the level of $\left({ }^{40} \mathrm{Ca}^{42} \mathrm{Ca}\right)^{++}$in that given spot and correct for it.

In addition to $\left({ }^{40} \mathrm{Ca}^{42} \mathrm{Ca}\right)^{++}$, we carefully evaluated the levels of scattered ions from the tails of ${ }^{40} \mathrm{Ca}^{+}$and ${ }^{40} \mathrm{CaH}^{+}$at $m / e=$ 41. The former, which was not accounted for in Srinivasan et al. (1996), was found at $\approx 3 \times 10^{-10} \times{ }^{40} \mathrm{Ca}^{+}$by measuring in steps of $0.2 \mathrm{amu}$ between masses 40 and 41 , whereas the latter was estimated by measuring the signal at mass 41.95 and applying the following relationship (assuming the peak shape of ${ }^{42} \mathrm{Ca}^{+}$ on the low-mass side is the same as that of ${ }^{40} \mathrm{CaH}^{+}$):

$$
\left[{ }^{40} \mathrm{CaH}^{+}\right]_{\text {tail }}=\frac{[41.95]}{\left[{ }^{42} \mathrm{Ca}^{+}\right]} \times\left[{ }^{40} \mathrm{CaH}^{+}\right]
$$

Under our analytical condition, the ratio of scattered ions at $m / e=41$ to the intensity of ${ }^{40} \mathrm{CaH}^{+}$was found to be $3 \times$ $10^{-6}$. Such a correction is relatively minor $(<1 \%$ of the total counts) compared to that for $\left({ }^{40} \mathrm{Ca}^{42} \mathrm{Ca}\right)^{++}$due to full separation between ${ }^{40} \mathrm{CaH}^{+}$and ${ }^{41} \mathrm{~K}$. The dynamic background of the counting system was measured for $60 \mathrm{~s}$ at the beginning of each analytical cycle, and the typical count rates range from 0.02 to 0.05 counts $\mathrm{s}^{-1}$. This dynamic background was preferred over static background of $\sim 0.005$ counts $\mathrm{s}^{-1}$ measured overnight for $10 \mathrm{hr}$ at $60 \mathrm{~s}$ interval because the latter may lead to under correction. The true ${ }^{41} \mathrm{~K} /{ }^{39} \mathrm{~K}$ ratio of a spot was then obtained after summing up counts over the entire analysis (e.g., Ogliore et al. 2011) and stripping off the interferences:

$$
\begin{aligned}
& \left(\frac{{ }^{41} \mathrm{~K}^{+}}{{ }^{39} \mathrm{~K}^{+}}\right)_{\text {true }} \\
& \quad=\frac{[41]_{m}-\left[\frac{{ }^{40} \mathrm{Ca}^{43} \mathrm{Ca}^{++}}{{ }^{43} \mathrm{Ca}^{+}}\right] \times{ }^{42} \mathrm{Ca}^{+}-\left[{ }^{40} \mathrm{CaH}^{+}\right]_{\text {tail }}-\left[{ }^{40} \mathrm{Ca}^{+}\right]_{\text {tail }}-\text { bkgd }}{{ }^{39} \mathrm{~K}^{+}} .
\end{aligned}
$$

In our analytical protocol, a polished sample was sputtered with a $10 \mathrm{nA}{ }^{16} \mathrm{O}^{-}$primary beam, and secondary ions were collected by the axial electron multiplier (EM) in a peakjumping mode, with the mass sequence of $38.7,{ }^{39} \mathrm{~K}^{+},{ }^{41} \mathrm{~K}^{+}$, ${ }^{40} \mathrm{CaH}^{+},\left({ }^{40} \mathrm{Ca}^{43} \mathrm{Ca}\right){ }^{++},\left({ }^{40} \mathrm{Ca}^{27} \mathrm{Al}^{16} \mathrm{O}\right){ }^{++},{ }^{42} \mathrm{Ca}^{+}$, and ${ }^{43} \mathrm{Ca}^{+} .{ }^{40} \mathrm{Ca}$ was not measured to avoid additional uncertainties derived from the cross calibration between a Faraday cup and the axial EM. Before each analysis, $\sim 25$ minute presputtering was applied to the sample surface to minimize the contaminations. The field aperture width was set at $2500 \mu \mathrm{m}$ to block out scattered K ions from the vicinity of the analysis spot. An energy window of $50 \mathrm{eV}$ was used. To correct for the peak and magnetic field drifts during a long analysis, both mass calibration and surface charging compensation were performed every five cycles. The count time on ${ }^{41} \mathrm{~K}^{+}$and $\left({ }^{40} \mathrm{Ca}^{43} \mathrm{Ca}\right)^{++}$was set at $60 \mathrm{~s}$ to achieve sufficient counting statistics. Each measurement consisted of 25-50 cycles and required $\sim 2-4 \mathrm{hr}$ of analysis time. Two terrestrial calcite standards with high ${ }^{40} \mathrm{Ca} /{ }^{39} \mathrm{~K}$ ratios $\left(>10^{6}\right.$, see Figure 2$)$ were analyzed to ensure that the mass spectrometry and the interference correction scheme were properly performed. Although ${ }^{40} \mathrm{~K}$ was not measured, normal ${ }^{41} \mathrm{~K} /{ }^{39} \mathrm{~K}$ ratios within errors (0.072; Garner et al. 1975) obtained in all standard analyses indicated that the instrumental mass fractionation and the matrix effect on $\mathrm{K}$ isotope compositions were insignificant and would not affect the determination of ${ }^{41} \mathrm{~K}^{*}$ in extraterrestrial samples.

The relative sensitivity factor ( $\mathrm{RSF}$ ) of $\mathrm{Ca}$ to $\mathrm{K}$ was determined to be $2.53 \pm 0.01(2 \sigma)$ on a NIST 614 glass with known $\mathrm{Ca}$ and $\mathrm{K}$ concentrations $\left(\mathrm{CaO}=12 \mathrm{wt} \%\right.$ and $\mathrm{K}=30 \mu \mathrm{g} \mathrm{g}^{-1}$; NBS Tech Report 1982). Given that Ca isotopes exhibited very limited instrumental mass fractionation in the NBS 614 glass $\left(<2 \mathrm{amu}^{-1}\right)$, we calculated the true ${ }^{40} \mathrm{Ca} /{ }^{39} \mathrm{~K}$ ratio of a measured phase as follows:

$$
\left(\frac{{ }^{40} \mathrm{Ca}}{{ }^{39} \mathrm{~K}}\right)_{\text {true }}=\left(\frac{{ }^{42} \mathrm{Ca}^{+}}{{ }^{39} \mathrm{~K}^{+}}\right)_{\mathrm{m}} \times \frac{{ }^{40} \mathrm{Ca}}{{ }^{42} \mathrm{Ca}} \times \mathrm{RSF},
$$

where ${ }^{40} \mathrm{Ca} /{ }^{42} \mathrm{Ca}=151.03$ (Niederer \& Papanastassiou 1984). 
Table 1

Potassium Isotopic Compositions of E44 and E65 CAIs

\begin{tabular}{llc}
\hline \hline Sample & ${ }^{40} \mathrm{Ca} /{ }^{39} \mathrm{~K}( \pm 2 \sigma)$ & ${ }^{41} \mathrm{~K} /{ }^{39} \mathrm{~K}( \pm 2 \sigma)$ \\
\hline E44 px1 & $(5.38 \pm 0.13) \times 10^{5}$ & $0.07442 \pm 0.00154$ \\
E44 px2 & $(1.82 \pm 0.11) \times 10^{6}$ & $0.07644 \pm 0.00656$ \\
E44 px3 & $(7.24 \pm 0.28) \times 10^{5}$ & $0.07162 \pm 0.00269$ \\
E44 px4 & $(8.27 \pm 0.21) \times 10^{5}$ & $0.07612 \pm 0.00198$ \\
E44 px5 & $(8.37 \pm 0.63) \times 10^{6}$ & $0.08722 \pm 0.01766$ \\
E44 px6 & $(8.78 \pm 0.38) \times 10^{5}$ & $0.07681 \pm 0.00344$ \\
E44 px7 & $(3.67 \pm 0.18) \times 10^{6}$ & $0.08283 \pm 0.00744$ \\
E44 px8 & $(4.28 \pm 0.20) \times 10^{6}$ & $0.08184 \pm 0.00768$ \\
E44 px9 & $(7.37 \pm 0.21) \times 10^{5}$ & $0.07468 \pm 0.00214$ \\
E44 px10 & $(6.63 \pm 0.17) \times 10^{5}$ & $0.07112 \pm 0.00176$ \\
E44 px11 & $(6.13 \pm 0.13) \times 10^{5}$ & $0.07308 \pm 0.00142$ \\
E44 px12 & $(2.04 \pm 0.61) \times 10^{6}$ & $0.07943 \pm 0.00338$ \\
E44 px13 & $(1.74 \pm 0.02) \times 10^{5}$ & $0.07259 \pm 0.00054$ \\
E65 px1 & $(3.28 \pm 0.05) \times 10^{5}$ & $0.07405 \pm 0.00084$ \\
E65 px2 & $(1.08 \pm 0.01) \times 10^{5}$ & $0.07259 \pm 0.00052$ \\
E65 px3 & $(8.15 \pm 0.26) \times 10^{5}$ & $0.07577 \pm 0.00232$ \\
E65 px4 & $(3.93 \pm 0.07) \times 10^{5}$ & $0.07296 \pm 0.00102$ \\
E65 px5 & $(1.38 \pm 0.22) \times 10^{7}$ & $0.10169 \pm 0.04468$ \\
E65 px6 & $(1.38 \pm 0.01) \times 10^{5}$ & $0.07218 \pm 0.00048$ \\
E65 px7 & $(7.38 \pm 0.06) \times 10^{4}$ & $0.07198 \pm 0.00332$ \\
E65 px8 & $(1.45 \pm 0.05) \times 10^{6}$ & $0.07394 \pm 0.00332$ \\
E65 px9 & $(7.20 \pm 0.18) \times 10^{5}$ & $0.07196 \pm 0.00184$ \\
E65 px10 & $(6.27 \pm 0.14) \times 10^{5}$ & $0.07359 \pm 0.00148$ \\
E65 mel1 & $(2.04 \pm 0.09) \times 10^{6}$ & $0.08046 \pm 0.00394$ \\
E65 mel2 & $(5.43 \pm 0.11) \times 10^{5}$ & $0.07552 \pm 0.00114$ \\
E65 mel3 & $(1.67 \pm 0.07) \times 10^{6}$ & $0.07756 \pm 0.00344$ \\
E65 mel4 & $(9.70 \pm 0.03) \times 10^{5}$ & $0.07205 \pm 0.00222$ \\
E65 me15 & $(1.90 \pm 0.07) \times 10^{6}$ & $0.07164 \pm 0.00309$ \\
E65 me16 & $(2.38 \pm 0.17) \times 10^{5}$ & $0.07242 \pm 0.00138$ \\
E65 mel7 & $(5.57 \pm 0.14) \times 10^{6}$ & $0.07396 \pm 0.00331$ \\
E65 me18 & $(7.98 \pm 0.49) \times 10^{6}$ & $0.07435 \pm 0.00144$ \\
E65 me19 & $(1.36 \pm 0.06) \times 10^{6}$ & $0.08432 \pm 0.01008$ \\
E65 mel10 & & $0.07078 \pm 0.00262$ \\
& & \\
& & \\
& &
\end{tabular}

Notes. The error of true ${ }^{41} \mathrm{~K} /{ }^{39} \mathrm{~K}$ was calculated by propagating the counting errors of stripped components $\left(\left({ }^{40} \mathrm{Ca}^{42} \mathrm{Ca}\right)^{++},{ }^{40} \mathrm{CaH}_{\text {tail }}^{+}\right.$, and $\left.{ }^{40} \mathrm{Ca}_{\text {tail }}^{+}\right)$into those of potassium isotopes. From counting statistics, $\left({ }^{40} \mathrm{Ca}^{42} \mathrm{Ca}\right)^{++}$contributes roughly $<2 \%$ to the final error of ${ }^{41} \mathrm{~K} /{ }^{39} \mathrm{~K}$, whereas the contributions from ${ }^{40} \mathrm{CaH}_{\text {tail }}^{+}$and ${ }^{40} \mathrm{Ca}_{\text {tail }}^{+}$are negligible because the two components comprise $<1 \%$ of the total signals at mass 41 (see Figure 4).

\section{RESULTS}

The potassium isotopic compositions of E44 and E65 are tabulated in Table 1 and plotted in Figure 3. Only fassaite and melilite yielded high enough ${ }^{40} \mathrm{Ca} /{ }^{39} \mathrm{~K}\left(>5 \times 10^{5}\right)$ for determination of ${ }^{41} \mathrm{~K}^{*}$, with ${ }^{39} \mathrm{~K}^{+}$count rates ranging from 15 to 1000 counts $\mathrm{s}^{-1}$. The $\left({ }^{40} \mathrm{Ca}^{42} \mathrm{Ca}\right)^{++}$interference comprises $5 \%-87 \%$ of the total measured signal at mass 41 , depending on the ${ }^{40} \mathrm{Ca} /{ }^{39} \mathrm{~K}$ ratio of the phase measured (Figure 4). In E44, an error-weighted-least-squares regression through all the data points yields $\left({ }^{41} \mathrm{Ca} /{ }^{40} \mathrm{Ca}\right)_{0}=(2.6 \pm 0.9) \times 10^{-9}\left(2 \sigma, \chi^{2}=2.0\right)$, and the intercept $\left({ }^{41} \mathrm{~K} /{ }^{39} \mathrm{~K}\right)_{0}=0.0721 \pm 0.0004$ is consistent with the terrestrial ratio. Similarly, low $\left({ }^{41} \mathrm{Ca} /{ }^{40} \mathrm{Ca}\right)_{0}=(1.4 \pm$ $0.6) \times 10^{-9}$ and normal $\left({ }^{41} \mathrm{~K} /{ }^{39} \mathrm{~K}\right)_{0}=0.0725 \pm 0.0002(2 \sigma)$ were found in the E65 CAI, although the scatter in the fitting appears to be larger $\left(\chi^{2}=3.6\right)$ than that of E44. The new values are about a factor of 7-10 lower than the previously claimed $(1.41 \pm 0.14) \times 10^{-8}$ by Srinivasan et al. (1996), but overlap ${ }^{41} \mathrm{Ca} /{ }^{40} \mathrm{Ca}=(4.1 \pm 2.0) \times 10^{-9}$ in EGG3 pyroxene determined by Ito et al. (2006).
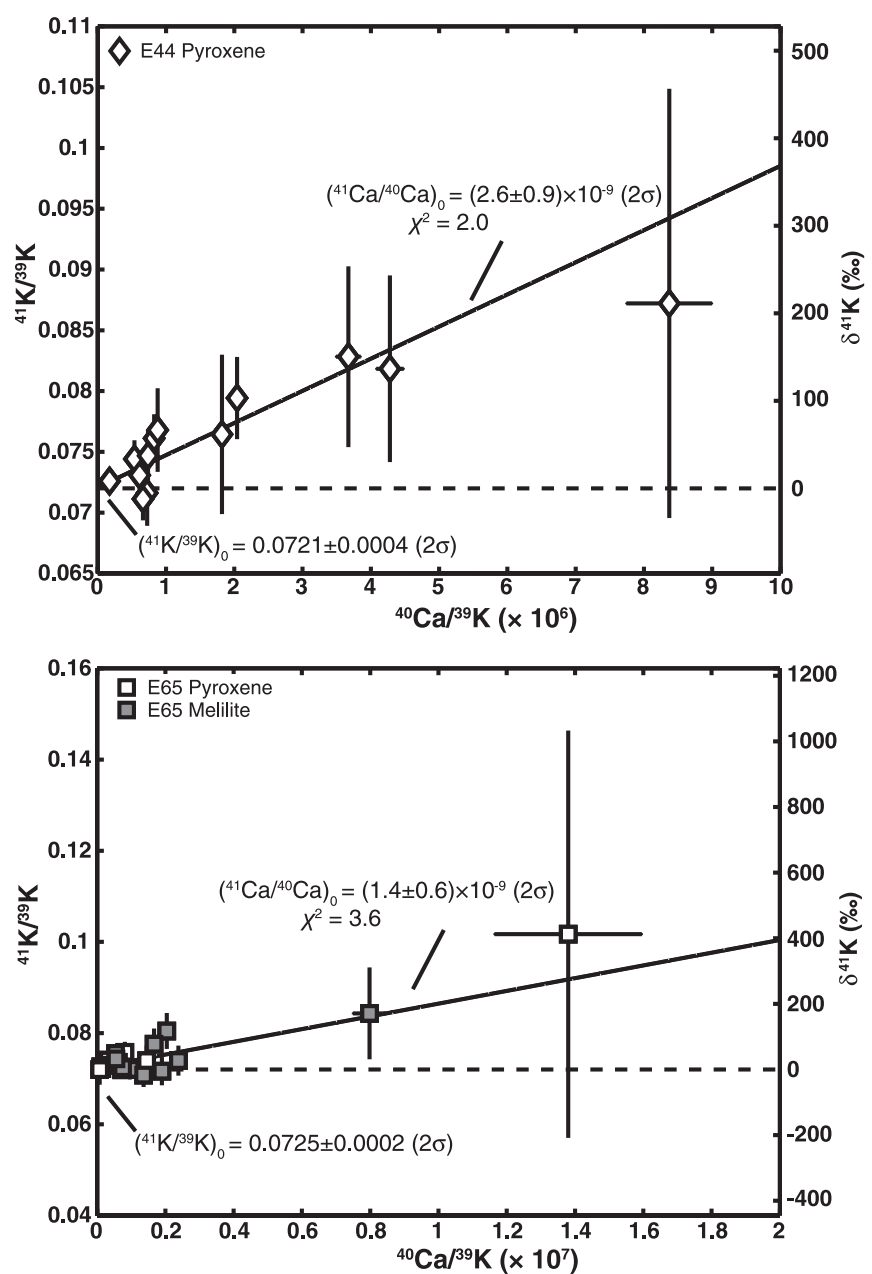

Figure 3. Isochron diagrams for E44 and E65 CAIs. $\delta^{41} \mathrm{~K}$ is defined as $\left(\left({ }^{41} \mathrm{~K} /{ }^{39} \mathrm{~K}\right) /(0.072)-1\right) \times 1000$. Errors are $2 \sigma$.

\section{DISCUSSION}

\subsection{A New Estimate for Initial ${ }^{41} \mathrm{Ca} /{ }^{40} \mathrm{Ca}$ in the Early Solar System}

The results obtained in this study are much lower than the previous value of Srinivasan et al. (1996), probably because the new SIMS enabled better separation between interferences and peaks of interest and more accurate corrections for the scattered ions at $m / e=41$. However, it should be noted that the two CAIs could have been thermally processed after their formation, as was implied by their lower-than-canonical ${ }^{26} \mathrm{Al} /{ }^{27} \mathrm{Al}$ ratios. Given that $\mathrm{K}$ self-diffusivity is only marginally slower than that of $\mathrm{Mg}$ in melilite (e.g., $6.74 \times 10^{-19}$ and $9.43 \times$ $10^{-19} \mathrm{~m}^{2} \mathrm{~s}^{-1}$ at $1200{ }^{\circ} \mathrm{C}$, respectively; Ito \& Ganguly 2004; the diffusion coefficient of $\mathrm{K}$ in fassaite is not available), the extent to which the $\mathrm{K}$ isotopes were disturbed should be similar to (or slightly less than) the $\mathrm{Mg}$ isotopes. This suggests that the ${ }^{41} \mathrm{Ca} /{ }^{40} \mathrm{Ca}$ ratios inferred from our measurements should not represent the true solar system initial. Applying the resetting times of $\sim 80,000$ years and $\sim 155,000$ years to E44 and E65, respectively, as were calculated by scaling their ${ }^{26} \mathrm{Al} /{ }^{27} \mathrm{Al}$ ratios back to $5.2 \times 10^{-5}$, we obtain converging values of ${ }^{41} \mathrm{Ca} /{ }^{40} \mathrm{Ca}=4.55_{-1.57}^{+2.60} \times 10^{-9}$ and $4.10_{-1.30}^{+2.04} \times 10^{-9}$. Such ${ }^{41} \mathrm{Ca} /{ }^{40} \mathrm{Ca}$ ratios are perfectly consistent with the inferred ${ }^{41} \mathrm{Ca} /{ }^{40} \mathrm{Ca}=(4.1 \pm 2.0) \times 10^{-9}$ by Ito et al. (2006) in the EGG3 CAI that is also characterized by the canonical ${ }^{26} \mathrm{Al} /{ }^{27} \mathrm{Al}$ of 


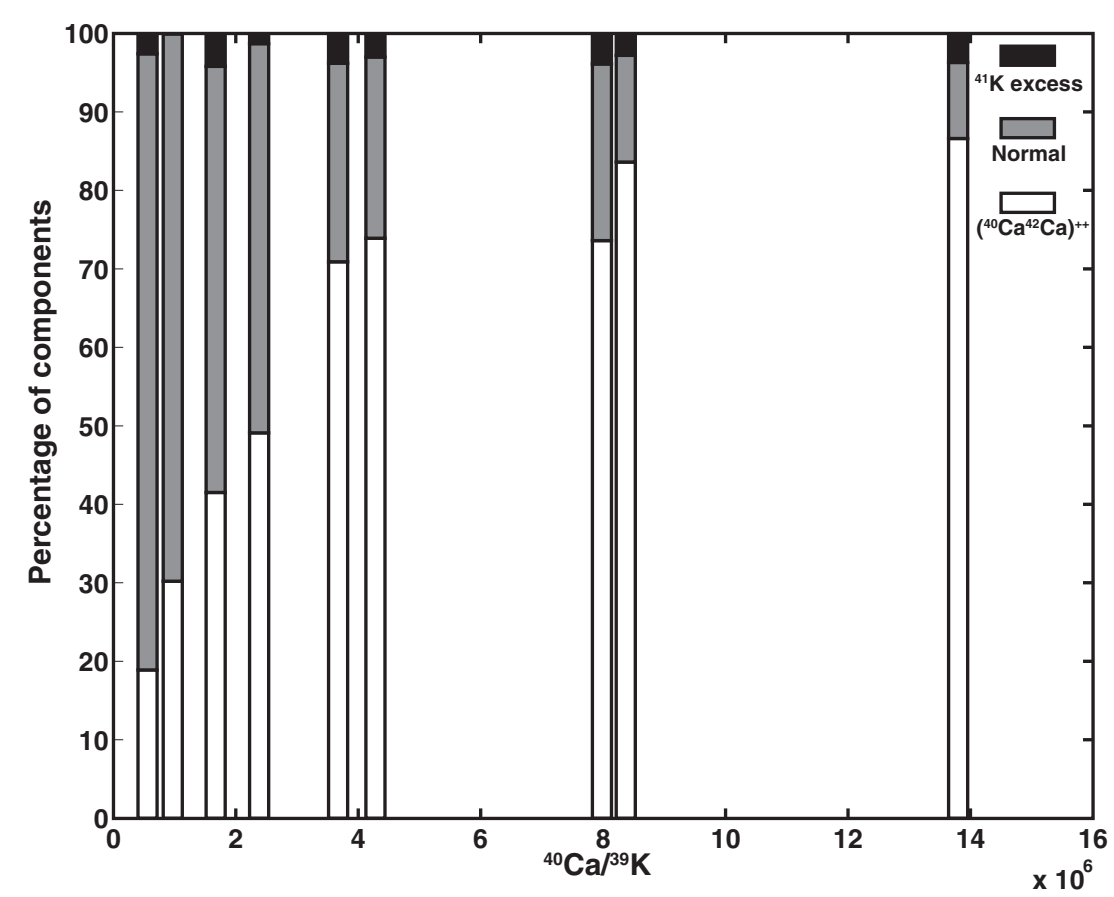

Figure 4. Fractions of different components that comprise the total signal at mass 41 in CAIs. The proportions of scattered ions from ${ }^{40} \mathrm{Ca}^{+}$and ${ }^{40} \mathrm{CaH}^{+}$are too small to be shown $(<1 \%)$.

$(5.29 \pm 0.39) \times 10^{-5}$ (Wasserburg et al. 2011). This surprisingly good agreement between CAIs from two different meteorites suggests synchronicity between ${ }^{41} \mathrm{Ca}$ and ${ }^{26} \mathrm{Al}$, albeit based on only three CAIs. As ${ }^{26} \mathrm{Al}$ is believed to have been homogeneously distributed at ${ }^{26} \mathrm{Al} /{ }^{27} \mathrm{Al}=5.2 \times 10^{-5}$ in the solar nebula during the epoch of CAI formation (Jacobsen et al. 2008; Villeneuve et al. 2009), this apparent synchronicity would not only imply a uniformity of ${ }^{41} \mathrm{Ca} /{ }^{40} \mathrm{Ca}=(4.1-4.5) \times 10^{-9}$ at the same time, but render ${ }^{41} \mathrm{Ca}$ chronology legitimate. Considering the error associated with each value, we propose that ${ }^{41} \mathrm{Ca} /{ }^{40} \mathrm{Ca}$ $\sim 4.2 \times 10^{-9}$ should be considered the best estimated initial ratio in the early solar system.

\subsection{Possible Origins for ${ }^{41} \mathrm{Ca}$}

The new initial ${ }^{41} \mathrm{Ca} /{ }^{40} \mathrm{Ca}$ ratio has important implications for the origin of this radionuclide and the timescale of solar system formation. Earlier explanations for ${ }^{41} \mathrm{Ca} /{ }^{40} \mathrm{Ca}=1.4 \times 10^{-8}$ involved a last-minute addition to the solar nebula, either by an injection from a stellar source or by in situ early solar system irradiation (e.g., Huss et al. 2009; Gounelle et al. 2001). This is because the expected "average" ${ }^{41} \mathrm{Ca} /{ }^{40} \mathrm{Ca}$ value in the interstellar medium (ISM) 4.5 billion years ago is only $\sim(2-8) \times$ $10^{-8}$, as can be calculated from Galactic Chemical Evolution (GCE; e.g., Wasserburg et al. 2006; Huss et al. 2009). Given the million-year (or longer) timescale for the formation of a molecular cloud and for a fragment of that cloud to collapse and form the Sun (Hartmann et al. 2001; Glover \& Mac Low 2007), ${ }^{41} \mathrm{Ca}$ directly inherited from the average ISM would have almost decayed away by the time of CAI formation. Even if ${ }^{41} \mathrm{Ca} /{ }^{40} \mathrm{Ca}=$ (2-8) $\times 10^{-8}$ happened to characterize the molecular cloud fragment from which the Sun was formed (which is possible since local ${ }^{41} \mathrm{Ca}$ abundances in different parts of the ISM could be significantly different from the average value), the time span between the collapse of that fragment and the solar system formation would still make ${ }^{41} \mathrm{Ca} /{ }^{40} \mathrm{Ca}$ lower than $1.4 \times 10^{-8}$ when CAIs formed.
Our revised initial ${ }^{41} \mathrm{Ca} /{ }^{40} \mathrm{Ca}$ ratio of $4.2 \times 10^{-9}$ for the early solar system falls below the GCE prediction by about a factor of 4-16, albeit there are large uncertainties associated with such calculations. Although it is impossible to completely rule out a last-minute input of ${ }^{41} \mathrm{Ca}$ from a dying star or protosolar irradiation, the need is certainly eased. It should also be pointed out that ${ }^{41} \mathrm{Ca}$ produced by in situ neutron capture on ${ }^{40} \mathrm{Ca}$ in the Efremovka parent body due to recent exposure to Galactic cosmic rays (GCRs) is still at least 10-fold lower than the observed ${ }^{41} \mathrm{Ca}$ abundance (Srinivasan et al. 1996).

\subsubsection{A Stellar Origin}

Many studies have proposed that ${ }^{26} \mathrm{Al}$ and ${ }^{41} \mathrm{Ca}$ (along with some other short-lived radioisotopes besides ${ }^{10} \mathrm{Be}$ ) could have been derived from a stellar source ( $\mathrm{SN}, \mathrm{AGB}$ star, or WR star) present shortly before the time of solar system formation (for a review, see Huss et al. 2009). The main arguments in support of such an origin largely come from the inferred presence of ${ }^{60} \mathrm{Fe}$ $\left(t_{1 / 2}=2.6 \mathrm{Myr}\right.$; Rugel et al. 2009), a radionuclide that requires exclusively a stellar origin, in the early solar system. By fine tuning the free decay time $(\Delta T)$ and dilution factor, one can arrive at a self-consistent solution for ${ }^{26} \mathrm{Al},{ }^{41} \mathrm{Ca}$, and ${ }^{60} \mathrm{Fe}$ to match their initial abundances in the early solar system ${ }^{5}$ (e.g., Huss et al. 2009). With the new ${ }^{41} \mathrm{Ca} /{ }^{40} \mathrm{Ca}$ ratio $\sim 3$ times lower than initially thought, a $\sim 0.15 \mathrm{Myr}$ increase in $\Delta T$ is required. This time increase would not change the abundances of ${ }^{26} \mathrm{Al}$ and ${ }^{60} \mathrm{Fe}$ because of their longer half-lives. Therefore, ${ }^{41} \mathrm{Ca}$ could in theory be brought into the nascent solar system along with ${ }^{26} \mathrm{Al}$ and ${ }^{60} \mathrm{Fe}$. The synchronicity as well as the correlated presence and absence between ${ }^{26} \mathrm{Al}$ and ${ }^{41} \mathrm{Ca}$ observed here and in earlier studies (e.g., Sahijpal \& Goswami 1998) could be understood in this context. However, very recent work on ${ }^{60} \mathrm{Fe}$ has shown that the initial ${ }^{60} \mathrm{Fe} /{ }^{56} \mathrm{Fe}$ ratio could have been more than an order of

\footnotetext{
$5{ }^{26} \mathrm{Al} /{ }^{27} \mathrm{Al}=5 \times 10^{-5},{ }^{41} \mathrm{Ca} /{ }^{40} \mathrm{Ca}=1.5 \times 10^{-8}$, and ${ }^{60} \mathrm{Fe} /{ }^{56} \mathrm{Fe} \sim 7 \times$
} $10^{-7}$ were usually used in such studies. 
magnitude lower than previously estimated $\left(\sim 10^{-8}\right.$; e.g., Tang $\&$ Dauphas 2012). Although one could still potentially obtain a self-consistent solution to explain the new abundances of ${ }^{41} \mathrm{Ca}$ and ${ }^{60} \mathrm{Fe}$ by fine-tuning different parameters of an injection model (e.g., $\Delta T$, dilution factor, nucleosynthetic yields, mass cut, etc.), whether the new model parameters are physical will need to be scrutinized. Considering the new ${ }^{60} \mathrm{Fe}$ results with our new ${ }^{41} \mathrm{Ca} /{ }^{40} \mathrm{Ca}$ initial ratio, it calls into question the need for a last-minute input from a dying star to explain the presence of ${ }^{41} \mathrm{Ca}$.

\subsubsection{Early Solar System Irradiation}

Evidence for intense irradiation occurring at the earliest stage of the solar system derives from the high but variable abundances of ${ }^{10} \mathrm{Be}$ in CAIs, with ${ }^{10} \mathrm{Be} /{ }^{9} \mathrm{Be}$ ranging from $3 \times 10^{-4}$ to $\sim 10^{-2}$, which were interpreted as a consequence of proton fluence variations (McKeegan et al. 2000; Chaussidon et al. 2006; Liu et al. 2010; Gounelle et al. 2012). With a favorable target chemistry (i.e., enriched in refractory elements, such as a CAI-like composition), irradiation processes involving nuclear reactions with energetic protons and alpha particles can be conducive to producing ${ }^{10} \mathrm{Be}$ and ${ }^{41} \mathrm{Ca}$, but not ${ }^{26} \mathrm{Al}$. It should be pointed out that the abundances of ${ }^{10} \mathrm{Be}$ and ${ }^{41} \mathrm{Ca}$ can still be inferred by means of isochrons in this scenario because of two reasons. First, the daughter elements of ${ }^{10} \mathrm{Be}$ and ${ }^{41} \mathrm{Ca}, \mathrm{B}$ and $\mathrm{K}$, respectively, are too volatile to condense out of the nebula gas at the CAI-forming temperatures ( $\sim 1400 \mathrm{~K}$ or above); therefore, the initial $\mathrm{Be} / \mathrm{B}$ and $\mathrm{Ca} / \mathrm{K}$ ratios of a $\mathrm{CAI}$ should be infinity. Any $\mathrm{B}$ and $\mathrm{K}$ seen in CAI minerals must have been due to late addition, either in the meteorite parent bodies or in the cold regions of solar nebula. Depending on the degree to which different mineral phases were contaminated, which resulted in variations in elemental ratios, an isochron can certainly be formed to infer the abundance of ${ }^{10} \mathrm{Be}$ or ${ }^{41} \mathrm{Ca}$. Second, some CAIs show isotopic and petrological evidence of remelting and recrystallization (e.g., MacPherson et al. 2012). These thermal processes can redistribute ${ }^{10} \mathrm{Be}$ and ${ }^{41} \mathrm{Ca}$ inside a $\mathrm{CAI}$ and make their initial abundances inferable through an isochron.

The two CAIs studied here are characterized by essentially the same ${ }^{10} \mathrm{Be} /{ }^{9} \mathrm{Be} \sim 8 \times 10^{-4}$ (Srinivasan \& Chaussidon 2012; McKeegan et al. 2001; unfortunately no ${ }^{10} \mathrm{Be} /{ }^{9} \mathrm{Be}$ data exist for EGG3). This indicates that, assuming similar Be contents in E44 and E65, they have suffered similar degrees of proton spallation (i.e., fluence), and therefore should have similar amounts of spallogenic ${ }^{41} \mathrm{Ca}$ produced within them. That the initial ${ }^{41} \mathrm{Ca} /{ }^{40} \mathrm{Ca}$ ratios in $\mathrm{E} 44$ and $\mathrm{E} 65$ are consistent with one another can be easily understood in this context. However, it has been shown that the proton fluence that yields ${ }^{10} \mathrm{Be} /{ }^{9} \mathrm{Be} \sim$ $9 \times 10^{-4}$ is capable of producing collateral ${ }^{41} \mathrm{Ca} /{ }^{40} \mathrm{Ca} \approx$ $2 \times 10^{-8}$ in a target with CAI chemistry, $\sim 4$ times higher than our preferred initial ratio (e.g., Lee et al. 1998). It is difficult to reconcile the overproduction of ${ }^{41} \mathrm{Ca}$ by irradiation unless one attributes it to the uncertainties associated with the calculations (e.g., uncertainties of cross section measurements, projectile compositions, and energy spectrum). Moreover, there are two other problems that an irradiation origin hypothesis is faced with. First, under the assumption of ${ }^{41} \mathrm{Ca}$ being produced by irradiation of solids, a variation in ${ }^{41} \mathrm{Ca} /{ }^{40} \mathrm{Ca}$ among different CAIs, as is the case for ${ }^{10} \mathrm{Be}$, is expected. This would mean that in CAIs with ${ }^{10} \mathrm{Be} /{ }^{9} \mathrm{Be}$ different from $9 \times 10^{-4},{ }^{26} \mathrm{Al}$ and ${ }^{41} \mathrm{Ca}$ would show different synchronicity from what we observed here. More coordinated high-precision measurements for ${ }^{41} \mathrm{Ca}$ and ${ }^{10} \mathrm{Be}$ are needed to settle this issue. The other problem is the existence of ${ }^{10} \mathrm{Be}$ in the samples devoid of ${ }^{26} \mathrm{Al}$ and ${ }^{41} \mathrm{Ca}$, for example, platy hibonite crystals from $\mathrm{CM}$ chondrites (e.g., Liu et al. 2009, 2010). It has been argued that ${ }^{26} \mathrm{Al},{ }^{41} \mathrm{Ca}$-free platy hibonite crystals could not have formed late, but instead are older than normal CAIs, due to the preservation of large anomalies (up to $\sim 40 \%)$ in neutron-rich isotopes $\left({ }^{48} \mathrm{Ca}\right.$ and ${ }^{50} \mathrm{Ti}$; e.g., Sahijpal \& Goswami 1998; Liu et al. 2009). The decoupling between ${ }^{41} \mathrm{Ca}$ and ${ }^{10} \mathrm{Be}$ in these solids requires a certain irradiation condition that was only conducive to the production of ${ }^{10} \mathrm{Be}$ but not of ${ }^{41} \mathrm{Ca}$. However, such a condition still remains unknown to us. Trapping of GCR ${ }^{10} \mathrm{Be}$ by the molecular cloud core could potentially be a solution for the decoupling between ${ }^{10} \mathrm{Be}$ and ${ }^{41} \mathrm{Ca}$ (Desch et al. 2004), but this model still faces challenges in explaining the observed variations in ${ }^{10} \mathrm{Be} /{ }^{9} \mathrm{Be}$ ratios in CAIs and platy hibonite crystals (Liu et al. 2010).

\subsubsection{Inheritance from the Molecular Cloud}

The third possible origin for ${ }^{41} \mathrm{Ca}$ in the early solar system involves an inheritance from the parent molecular cloud. The calculated average ${ }^{41} \mathrm{Ca} /{ }^{40} \mathrm{Ca}$ in the ISM is higher than our inferred solar system initial ratio. If the parent molecular cloud of the solar system was characterized by the ISM ${ }^{41} \mathrm{Ca} /{ }^{40} \mathrm{Ca}$ ratio, the abundance difference would allow for the possibility that ${ }^{41} \mathrm{Ca}$ was inherited from the molecular cloud and incorporated into CAIs after a free decay time of 0.2-0.4 Myr. Such a timescale is broadly consistent with the general free-fall timescale of a fragment of a molecular cloud to form a star, which is on the order of $10^{5}-10^{6}$ years depending on the density of the cloud fragment (e.g., Heitsch \& Hartmann 2008; Banerji et al. 2009). A homogeneous distribution of ${ }^{41} \mathrm{Ca}$ in the solar nebula and the concordant decay between ${ }^{26} \mathrm{Al}$ and ${ }^{41} \mathrm{Ca}$ would be natural consequences in this molecular cloud origin hypothesis. However, one should note that if ${ }^{41} \mathrm{Ca}$ had come in as part of molecular cloud material, it would have to predate any refractory materials that formed in the solar nebula. The lack of ${ }^{41} \mathrm{Ca}$ in platy hibonite crystals would certainly not fit into this picture, unless some later processes reset the potassium isotopes after ${ }^{41} \mathrm{Ca}$ had finished decaying in these crystals.

\section{CONCLUSION}

The reanalysis of the potassium isotopic compositions of E44 and E65 CAIs yielded inferred ${ }^{41} \mathrm{Ca} /{ }^{40} \mathrm{Ca}$ ratios of $(2.6 \pm 0.9) \times$ $10^{-9}$ and $(1.4 \pm 0.6) \times 10^{-9}(2 \sigma)$, respectively, a factor of 7-10 lower than previously determined by Srinivasan et al. (1996). By scaling the ${ }^{26} \mathrm{Al} /{ }^{27} \mathrm{Al}$ of the two CAIs back to $5.2 \times$ $10^{-5}$, we obtain an initial ${ }^{41} \mathrm{Ca} /{ }^{40} \mathrm{Ca}$ for the two CAIs merging around $4.2 \times 10^{-9}$. We consider this the best representative initial abundance of ${ }^{41} \mathrm{Ca}$ in the solar system. The synchronous decay between ${ }^{26} \mathrm{Al}$ and ${ }^{41} \mathrm{Ca}$ implies that the two radionuclides were homogeneously distributed in the solar nebula at least in the formation regions of refractory minerals and therefore they both could be used as chronometers. However, the low abundance of ${ }^{41} \mathrm{Ca}$ makes an understanding of its astrophysical origins more difficult than it used to be. More measurements for ${ }^{41} \mathrm{Ca} /{ }^{40} \mathrm{Ca}$ in CAIs are certainly needed to shed light on which source contributed the most to the ${ }^{41} \mathrm{Ca}$ inventory in the solar nebula.

We thank Matthieu Gounelle for invaluable comments and the referee for a critical review, which greatly improve the presentation of this paper. This work was supported by grants from National Science Council (Taiwan, ROC) NSC 101-2116- 
M-001-014 (M.-C. Liu), from European Research Council (ERC grant FP7/20072013 Grant Agreement No. [226846] Cosmochemical exploration of the first two Million Years of the Solar System-CEMYSS), -ANR-08-BLAN-0260-CSD6 (M. Chaussidon), and from NASA Cosmochemistry (K. D. McKeegan), for which we are appreciative. This is CRPG publication number 2207.

\section{REFERENCES}

Arnould, M., Goriely, S., \& Meynet, G. 2006, A\&A, 453, 653

Banerji, M., Viti, S., Williams, D. A., \& Rawlings, J. M. C. 2009, ApJ, 692, 283

Boss, A. P. 2007, ApJ, 660, 1707

Boss, A. P. 2011, ApJ, 739, 61

Chaussidon, M., Robert, F., \& McKeegan, K. D. 2006, Geochim. Cosmochim. Acta, 70, 224

Dauphas, N., \& Chaussidon, M. 2011, Annu. Rev. Earth Planet. Sci., 39,351

Desch, S. J., Connolly, H. C., Jr., \& Srinivasan, G. 2004, ApJ, 602, 528

Garner, E. L., Murphy, T. J., Gramlich, J. W., Paulsen, P. J., \& Barnes, I. L. 1975, J. Res. Natl. Bur. Stand., 79A, 713

Glover, S. C. O., \& Mac Low, M.-M. 2007, ApJ, 659, 1317

Goswami, J. N., Srinivasan, G., \& Ulyanov, A. A. 1994, Geochim. Cosmochim. Acta, 58, 431

Gounelle, M., Chaussidon, M., \& Rollion-Bard, C. 2012, ApJ, in press

Gounelle, M., Shu, F. H., Shang, H., et al. 2001, ApJ, 548, 1051

Gounelle, M., Shu, F. H., Shang, H., et al. 2006, ApJ, 640, 1163

Hartmann, L., Ballesteros-Paredes, J., \& Bergin, E. A. 2001, ApJ, 562, 852

Heitsch, F., \& Hartmann, L. 2008, ApJ, 689, 290

Huss, G. R., Meyer, B. S., Srinivasan, G., Goswami, J. N., \& Sahijpal, S. 2009, Geochim. Cosmochim. Acta, 73, 4922

Hutcheon, I. D., Armstrong, J. T., \& Wasserburg, G. J. 1984, in Lunar Planet. Sci. Conf., 15, 387

Ito, M., \& Ganguly, J. 2004, Meteorit. Planet. Sci., 39, 1911

Ito, M., Nagasawa, H., \& Yurimoto, H. 2006, Meteorit. Planet. Sci., 41, 1871

Jacobsen, B., Yin, Q.-Z., Moynier, F., Amelin, Y., et al. 2008, Earth Planet. Sci. Lett., 272, 353
Jörg, G., Amelin, Y., Kossert, K., \& Lierse v. Gostomski, C. 2012, Geochim. Cosmochim. Acta, 88, 51

Korschinek, G., Bergmaier, A., Faestermann, T., et al. 2010, Nucl. Instrum. Methods Phys. Res. B, 268, 187

Lee, T., Shu, F. H., Shang, H., Glassgold, A. E., \& Rehm, K. E. 1998, ApJ, 506,898

Liu, M.-C., McKeegan, K. D., Goswami, J. N., et al. 2009, Geochim. Cosmochim. Acta, 73, 5051

Liu, M.-C., Nittler, L. R., Alexander, C. M. O’D., \& Lee, T. 2010, ApJ, 719, L99

MacPherson, G. J., Kita, N. T., Ushikubo, T., Bullock, E. S., \& Davis, A. M. 2012, Earth Planet. Sci. Lett., 331, 43

McKeegan, K. D., Chaussidon, M., Krot, A. N., et al. 2001, in Lunar Planet. Sci. Conf., 32, 2175

McKeegan, K. D., Chaussidon, M., \& Robert, F. 2000, Science, 289, 1334

Meyer, B. S. 2005, in ASP Conf. Ser. 341, Chondrites and Protoplanetary Disk, ed. A. N. Krot, E. R. Scott, \& B. Reipurth (San Francisco, CA: ASP), 515

National Bureau of Standards 1982, National Bureau of Standards Certificate of Analysis-Standard Reference Materials: 614 and 615 Wafers

Niederer, F. R., \& Papanastassiou, D. A. 1984, Geochim. Cosmochim. Acta, 48,1279

Ogliore, R. C., Huss, G. R., \& Nagashima, K. 2011, Nucl. Instrum. Methods Phys. Res. B, 269, 1910

Rugel, G., Faestermann, T., Knie, K., et al. 2009, Phys. Rev. Lett., 103, 072502

Sahijpal, S., \& Goswami, J. N. 1998, ApJ, 509, 137

Sahijpal, S., Goswami, J. N., \& Davis, A. M. 2000, Geochim. Cosmochim. Acta, 64, 1989

Sahijpal, S., Goswami, J. N., Davis, A. M., Lewis, R. S., \& Grossman, L. 1998, Nature, 391, 559

Srinivasan, G., Sahijpal, S., Ulyanov, A. A., \& Goswami, J. N. 1996, Geochim. Cosmochim. Acta, 60, 1823

Srinivasan, G., \& Chaussidon, M. 2012, Earth Planet. Sci. Lett., in press

Tang, H., \& Dauphas, N. 2012, in Lunar Planet. Sci. Conf., 43, 1703

Villeneuve, J., Chaussidon, M., \& Libourel, G. 2009, Science, 325, 985

Wasserburg, G. J., Busso, M., Gallino, R., \& Nollett, K. M. 2006, Nucl. Phys. A, 777,5

Wasserburg, G. J., Wimpenny, J., \& Yin, Q.-z. 2011, Workshop on Formation of the First Solids in the Solar System, 9038

Young, E. D., Simon, J. I., Galy, A., et al. 2005, Science, 308, 227 